\title{
Effects of operant conditioning on frequency of polysyllabic words and speed of response'
}

A. RALPH HAKSTIAN and C. ANN BRICKNER, ${ }^{2}$ Laboratory of Educational Research, University of Colorado, Boulder, Colo. 80302

Subjects were given various combinations of investigator and positive and/or negative reinforcement for polysyllabic words during free verbalization. In comparing frequency of reinforced responses, reinforcement and investigator effects were nonsignificant; however, combinations of positive and negative reinforcement interacted with investigator. Speed of response was unaffected by reinforcement and investigator, but both positive and negative reinforcement interacted with investigator.

Greenspoon's (1955) early research on verbal conditioning indicated that a positively reinforcing stimulus "mmm-hmmm" from E following plural nouns emitted by Ss in a free verbalizing situation increased the frequency of both plural nouns and other words, while "huh-uh" decreased the frequency of plural nouns, and increased the frequency of other words. Sidowski (1954), reinforcing plural nouns with a light blink, concluded that conditioning took place and did so without awareness by the Ss. In subsequent studies, investigators have reinforced certain initial pronouns in sentences (Levin, 1961; Spielberger \& Levin, 1962; Spielberger, Levin, \& Shepard, 1962) or animate nouns (Maltzman, Seymore, \& Licht, 1962).

Subject awareness of the response-reinforcement contingency has been investigated with conflicting results. Studies by Krieckhaus \& Erikson (1960); Matarazzo, Saslow, \& Pareis (1960); Levin (1961); Maltzman, Seymore, \& Licht (1962) showed a degree of learning without awareness, whereas other studies (Spielberger \& DeNike, 1962; Spielberger \& Levin, 1962; Spielberger, Levin, \& Shepard, 1962; Wolpin \& Milgram, 1962; Dean \& Hiesinger, 1964; Lanyon, 1964; Dixon, 1966) indicate that either partial or total awareness is critical and that failure to determine adequately awareness of Ss may have led to erroneous interpretations of the construct model.

Reinforcement has varied from both positive and negative (Meyer \& Crum, 1966) to positive only (Maltzman, Seymore, \& Licht, 1962) with little difference in effect, although Curry (1960) and Meyer \& Crum (1966) noticed some advantage for a combination of positive and negative reinforcement.

The present study involved reinforcement by two Es of polysyllabic words (a difficult enough contingency to effectively control awareness) by positive, negative, positive and negative, or no reinforcement to distinct groups. Both frequency of reinforced responses and speed of response were analyzed.

\section{SUBJECTS}

Twenty-four sophomore-level Ss were randomly selected and assigned to one of eight experimental conditions.

\section{PROCEDURE}

The Ss were evenly and randomly divided between the two Es. Ss freely verbalized 200 words. The first 50 words were unreinforced to provide data on an operant level of both number of polysyllabic words and speed of response for each $S$; these data were used as covariates in the two analyses. Number of polysyllabic words and number of seconds used by Ss in the last 150 words were recorded and constituted the two dependent variables. Each $\mathrm{E}$ administered four treatments -no reinforcement, positive reinforcement only (for polysyllabic words), negative reinforcement only (for monosyllables), and both positive and negative reinforcement. The positive reinforcement consisted of "mmm-huh $\uparrow "$; the negative, "mmm-mmm $\downarrow$." Ss were questioned extensively following the experimental period; none. was able to verbalize the response-reinforcement contingency.

\section{DESIGN}

A 2 by 2 by 2 factorial design was used with two levels of positive reinforcement (given or absent), negative reinforcement, and investigator. A mixed model analysis of covariance (ANCOVA) was called for, with the reinforcement factors fixed, the investigator factor, random. For the analysis of number of polysyllabic words uttered, basal operant level of polysyllables (number in the first 50 unreinforced responses) was covaried out. In the analysis of speed of response, number of seconds taken uttering the first 50 unreinforced responses was covaried.

\section{RESULTS AND DISCUSSION \\ Number of Polysyllabic Words Uttered}

From the mixedeffects model ANCOVA, the three main effects tested were nonsignificant: Positive Reinforcement $(F=$ $0.00002, p>.25)$, Negative Reinforcement $(F=3.15574$, $\mathrm{p}>.25)$, and Investigator $(\mathrm{F}=0.02327, \mathrm{p}>.25)$. The three two-way interactions were also nonsignificant: Positive by Negative Reinforcement $(F=1.73843, p>.25)$, Positive Reinforcement by Investigator $(F=2.57264, p>.10)$, and Negative Reinforcement by Investigator $(F=0.83591$, $\mathrm{p}>.25)$. The three-way interaction effect-Positive by Negative Reinforcement by Investigator-was statistically significant $(\mathrm{df}=1 / 15, \mathrm{~F}=7.27941, \mathrm{p}<.05)$. Results, then, fail to support the hypotheses that positive or negative reinforcement is effective in shaping this verbal response, or that investigator differences over treatment groups make a difference in number of polysyllabic words uttered. Also, the results show that positive and negative reinforcement tend to interact neither with each other nor with investigator.

The significant three-way interaction is graphed in Fig. 1. It can be seen from this diagram that the combinations of positive and negative reinforcement led to different effects from Investigator 1 to 2 .

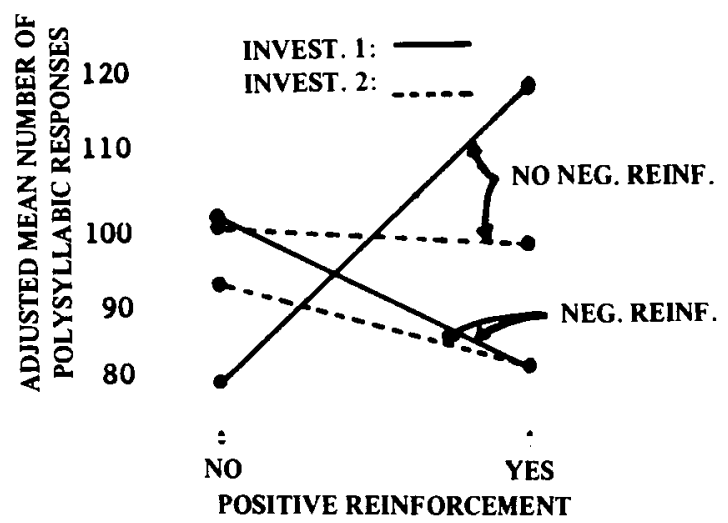

Fig. 1. Diagram of Positive by Negative Reinforcement by Investigator interaction. 
Speed of Response of Words Uttered

From the ANCOVA of this dependent variable, the three main effects tested were again nonsignificant: Positive Reinforcement $(F=0.00904, p>.25)$, Negative Reinforcement $(F=0.13729, p>.25)$, and Investigator $(F=0.10469$, $p>.25$ ), indicating that speed of verbal response tends not to be affected by either positive or negative reinforcement or by one investigator as opposed to another. The Positive by Negative Reinforcement interaction effect and the three-way interaction effect were also nonsignificant $(F=0.86374$, $p>.25 ; F=2.54717, p>.10$, respectively). The results show, however, that both positive and negative reinforcement tend to interact, disordinally, with investigator $(\mathrm{df}=1 / 15$, $\mathrm{F}=5.78087, \mathrm{p}<.05 ; \mathrm{F}=6.54117, \mathrm{p}<.05$, respectively); i.e., the effects on response rate of positive reinforcement of polysyllabic words, or negative reinforcement of monosyllables are quite different depending upon the investigator giving the reinforcement: with Investigator 1 , positive reinforcement depressed response rate, whereas with Investigator 2, positive reinforcement tended to increase rate of response. With Investigator 1 , negative reinforcement appeared to facilitate response rate, whereas with Investigator 2, negative reinforcement tended to depress the speed of response. An interesting, although inexplicable. result was that the overall fastest response rate (across investigators) was associated with both positive and negative reinforcement, the schedule that resulted in the smallest number of polysyllabic responses in the first analysis.

\section{CONCLUSIONS}

In summary, the results are not consistent with some published findings mentioned in the first three paragraphs. This inconsistency, as well as the three-way interaction noted in the first analysis, would seem to indicate the need for a more rigorous delineation of the reinforcing stimulus employed in studies of this sort. Also, the inconsistency may involve the question of awareness. It would seem that, for learning to occur, awareness, although not necessarily resulting in verbalization, must take place at some level in the organism, and, in the present study, the nature of the response reinforced may preclude this entirely. Finally, the investigator effect may be of considerable significance in studies of this nature. It is suggested, then. that future research in verbal conditioning would be profitably focused on the nature of the reinforcing stimulus and of awareness as well as on the effect of the investigator.

\section{REFERENCES}

CURRY, C. The effects of verbal reinforcement combinations on learning in children. Journal of Experimental Psychology, 1960, 59, 434.

DEAN, S. J., \& HIESINGER, L. Operant level awareness and the Greenspoon ef fect. Psychological Reports, 1964, 15, 931-938.

DIXON, T. R. A complex reinforcement contingency: The control of awareness in verbal conditioning. Journal of Verbal Learning \& Verbal Behavior, 1966, 5, 514-521.

GREENSPOON, J. The reinforcing effect of two spoken sounds on the frequency of two responses. American Journal of Psychology, 1955, 68, 409-416.

KRIECKHAUS, E. E., \& ERIKSON, C. W. A study of awareness and its effect on learning and generalization. Journal of Personality, 1960, 28, 503-517.

LANYON, R. I. Verbal conditioning and awareness in a sentence construction task. American Journal of Psychology, 1964, 77, 472-475.

MALTZMAN, I., SEYMORE, S., \& LICHT, L. Verbal conditioning of common and uncommon word associations. Psychological Reports, $1962,10,363-369$.

MATARAZZO, J. D., SASLOW, G., \& PAREIS, E. N. Verbal conditioning of two response classes: Some methodological considerations. Journal of Abnormal \& Social Psychology, 1960, 71, 190206.

MEYER, M. E., \& CRUM, D. M. Verbal conditioning with "positive" and "positive and negative" reinforcement. Psychonomic Science, 1966, 4, 59-60.

SIDOWSKI, J. B. Influence of awareness of reinforcement on verbal conditioning. Journal of Experimental Psychology, 1954, 48, 355-360.

SPIELBERGER, C. D., \& DENIKE, L. D. Operant conditioning of plural nouns: A failure to replicate the Greenspoon effect. Psychological Reports, 1962, 11, 355-366.

SPIELBERGER, C. D., \& LEVIN, S. M. What is learned in verbal conditioning? Journal of Verbal Learning \& Verbal Behavior, 1962, 1, $125-132$.

SPIELBERGER, C. D., LEVIN, S: M., \& SHEPARD, M. C. The effects of awareness and attitude toward the reinforcement on the operant conditioning of verbal behavior. Journal of Personality, 1962, 30, 106-120.

WOLPIN, M., \& MILGRAM, N. Learning without awareness and awareness without learning. Psychological Reports, 1962, 10, 867-874. NOTES

1. The costs of production of this paper were partially met by the U. S. Office of Education Grant No. OEG-4-6-061860-0812.

2. Now at Educational Development Laboratory, McGraw-Hill Book 